\title{
USE OF TURKISH BENTONITE MINERAL AS AN ADDITIVE FOR POLY(LACTIC ACID) BASED BIO-COMPOSITE MATERIALS
}

\author{
Ali Sinan DİKE ${ }^{1, *}$ \\ ${ }^{1}$ Department of Materials Engineering, Faculty of Engineering, Adana Alparslan Turkes Science and Technology University, \\ Adana, Turkey
}

\begin{abstract}
In this study, Turkish bentonite (BN) mineral is subjected to silane treatment in order to enhance its compatibility for poly(lactic acid) (PLA). Neat and surface silanized BN powders are compounded with PLA using melt blending process at the concentrations of 5, 10, 15 and $20 \mathrm{wt} \%$. Surface characteristics of BN samples are examined by infrared spectroscopy. Mechanical, thermo-mechanical, water resistance, melt flow and morphological investigations of composites are performed by tensile and impact tests, dynamic mechanical analysis (DMA), water absorption test, melt flow rate test (MFR) and scanning electron microscopy (SEM) analysis, respectively. Mechanical test results show that BN additions lead to increase in tensile strength and modulus of PLA. The maximum improvement is obtained for $15 \mathrm{wt} \%$ of silanized BN containing composite. Silanized BN filled PLA displays higher impact performance compared to untreated BN sample. Impact energy values of composites increase with increase in loading ratio. Silanized BN containing composite with $20 \mathrm{wt} \%$ concentration gives the highest storage modulus according to the DMA study. Glass transition temperature of PLA is improved by the inclusions of all BN samples. Additions of BN make slight decreases on MFR value of PLA. However, these reductions are found to be negligible in terms of its effect on processing of material. Water uptakes of composites are found to be higher than that of PLA. Composites containing silanized BN have lower water absorption values than neat BN samples due to the hydrophobicity of silicon containing surface. SEM characterization reveals that more homogeneous dispersion in PLA matrix is observed for silane treated BN compared to neat BN particles thanks to improvement of interfacial adhesion between BN and PLA matrix.
\end{abstract}

Keywords: Bentonite, Poly (lactic acid), Bio-composites, Extrusion, Polymer composites

\section{INTRODUCTION}

Fabrication of environmental-friendly materials has been widely studied by scientific and industrial researchers due to ecological issues of recent decades. Composite materials are consisting natural products are named as bio-composites and they are developed for the main purpose of the replacement of conventional petroleum related composites. Bio-composites have numerous advantages including low weight, practical fabrication, biodegradability and recyclability. The materials derived from renewable resources have found wide usage in industrial field such as packaging, automotive, textile and outdoor applications [1-4].

Poly (lactic acid) (PLA) is a well-known renewable polymer. The ability of this commercialized biopolymer is the reduction of the disposal problem which is encountered mainly in packaging products [5, 6]. Reinforcing bio-polymers with suitable additives is a popular research topic nowadays since biopolymers exhibit some limitations such as low toughness, poor thermal stability and narrow processing window [7-10].

Natural minerals are used as additives for plastics because of they have low cost and easy to handle properties. Effect of mineral additives to polymers is related with some factors including particle size, concentration, shape and interface adhesion with matrix [11-13]. Improvement of interfacial adhesion and compatibility between mineral additives and polymer matrix plays a key role in obtaining composite materials with required performances [14-17].

*Corresponding Author: asdike@atu.edu.tr

Received: 30.04.2019 Published: 31.03.2020 
Bentonite mineral is obtained mostly in volcanic eruptions as the form of ash particles. Turkey has a large portion of bentonite reserves among other countries such as Australia, USA, Greece and India. Ankara, Tokat, Ordu, Giresun and Balikesir are the main areas where Turkish bentonite reserves are found [1820]. Bentonite has a potential of use as an additive for polymers due to having high level of plasticity [13]. In the literature, several polymers are compounded with bentonite including polyethylene [21-24], polypropylene [25-27], polystyrene [28], polycarbonate [29], and styrene-butyl-acrylate copolymer [30].

The main purpose of this research study is the investigation of mechanical, thermo-mechanical, water resistance, melt flow and morphological performance of Turkish bentonite reinforced PLA bio-composites in order to propound of their large scale fabrication in industrial fields such as packaging and outdoor products. Bentonite powder is subjected to silane modification for the aim of improvement of compatibility between additive and PLA matrix. Modified and neat bentonite surfaces are characterized using infrared spectroscopy (IR) in attenuated total reflectance (ATR) mode. Composites are fabricated by extrusion process and test samples are prepared using injection molding. Beside of the mechanical (tensile and impact tests) and thermo-mechanical (dynamic mechanical analysis) studies, water absorption tests are conducted to investigate the possible use of composites for outdoor applications. Melt flow rate test is performed in order to understand their processability and scanning electron microscopy (SEM) is applied for the characterization of morphological properties of composites.

\section{MATERIALS AND METHODS}

\subsection{Materials}

The commercial PLA is supplied from Natureworks LLC, USA under the trade name of Ingeo biopolymer 6100D. It has density of $1.24 \mathrm{~g} / \mathrm{cm}^{3}$ and relative viscosity of 3.1 according to CD Internal viscotek method. Na-activated bentonite powder is obtained from Reşadiye, Tokat region and it is supplied by Karakaya Bentonite, Turkey. BN has specific gravity of $2.4 \mathrm{~g} / \mathrm{cm}^{3}$ and volume mean diameter of $20.6 \mu \mathrm{m}$. Chemical composition of BN sample is given in Table 1 [29]. Silane coupling agent (aminopropyltriethoxysilane) and ethanol are purchased from Merck AG, Germany.

Table 1. Chemical composition of bentonite sample.

\begin{tabular}{ccc}
\hline Compound & Test Method & Composition (wt\%) \\
\hline $\mathrm{SiO}_{2}$ & EN 12902 & $50-70$ \\
$\mathrm{Al}_{2} \mathrm{O}_{3}$ & EN 12485 & $10-20$ \\
$\mathrm{MgO}$ & EN 12485 & $1.0-4.5$ \\
$\mathrm{CaO}$ & EN 12485 & $0.5-4.0$ \\
$\mathrm{Na}_{2} \mathrm{O}$ & EN 12485 & $0.5-3.0$ \\
\hline
\end{tabular}

\subsection{Surface Silanization of Bentonite}

Bentonite powders are mixed in $2 \mathrm{wt} \%$ of aminopropyltriethoxysilane/ethanol solution for 2 hours at room temperature. After mixing, samples are washed and dried at $70^{\circ} \mathrm{C}$ overnight. Neat and silane treated bentonite samples are named as $\mathrm{BN}$ and $\mathrm{BN}(\mathrm{S})$, respectively.

\subsection{Production of Composites}

Bentonite containing PLA based composites are produced using DSM Xplore micro-compounder at $210^{\circ} \mathrm{C}$ for 5 minutes with the mixing speed of $100 \mathrm{rpm}$. Unfilled PLA is also mixed under the same conditions and named as PLA. Concentrations of BN and BN (S) in PLA matrix are 5, 10, 15 and 20 $\mathrm{wt} \%$. Test samples of the composites are prepared by Daca Instruments micro-injection molding machine at a barrel and mold temperatures of $215^{\circ} \mathrm{C}$ and $40^{\circ} \mathrm{C}$, respectively. The photograph of shaped composites is displayed in Figure 1. 


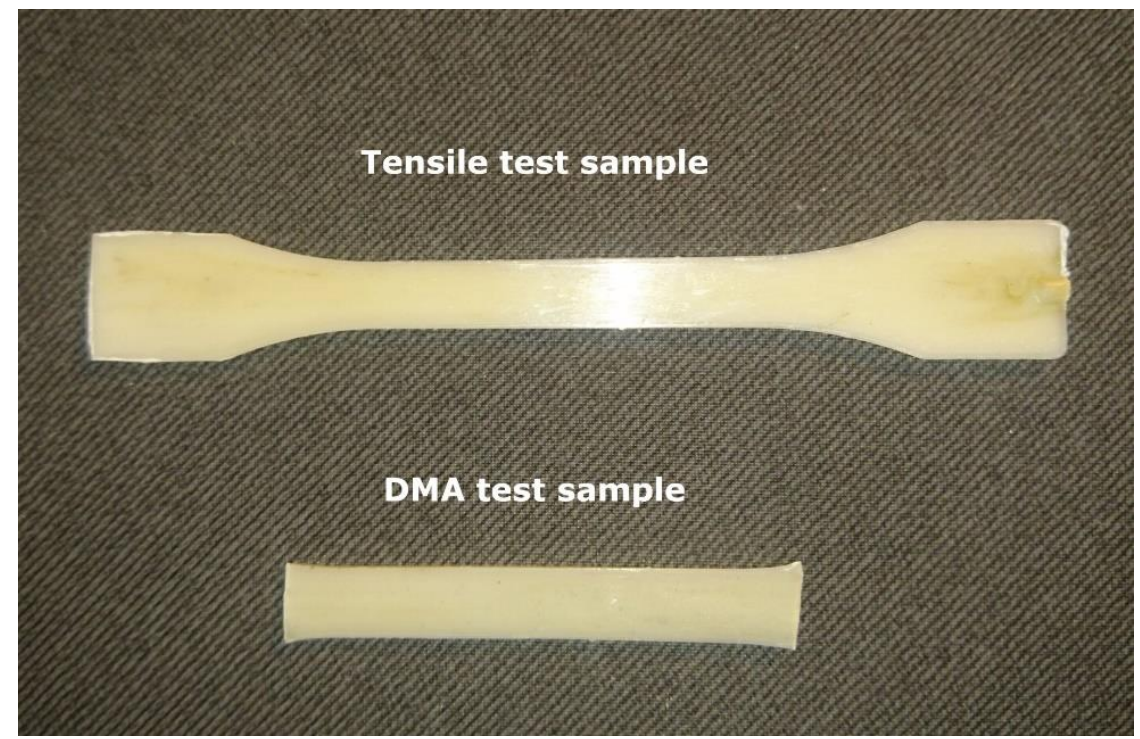

Figure 1. Photograph of prepared test samples.

\subsection{Characterization Methods}

Infrared spectroscopy (IR) technique in ATR mode (Bruker Optics, 66/S series) is used to investigate the surface. Tensile tests are done using Lloyd LR $30 \mathrm{~K}$ universal tensile testing device with $5 \mathrm{kN}$ load cell and crosshead speed of $5 \mathrm{~cm} / \mathrm{min}$. Tensile strength, percentage strain and tensile modulus values are recorded as minimum of three samples with the standard deviations. Impact test is performed by Coesfeld material impact tester with the $4 \mathrm{~J}$ pendulum. DMA technique is carried out using Perkin Elmer DMA 8000 in dual cantilever bending mode under the inert nitrogen atmosphere. Temperature range of analysis is between $-150^{\circ} \mathrm{C}$ and $200^{\circ} \mathrm{C}$ at the heating rate of $10^{\circ} \mathrm{C} / \mathrm{min}$. Melt flow rates (MFR) of samples are measured using Coesfeld meltfixer LT. The tests are performed with the standard load of $5 \mathrm{~kg}$ at $210^{\circ} \mathrm{C}$. During water uptake test, samples are conditioned and immersed in water bath at room temperature according to test procedure of ASTM D570. Then, they are taken out from water and weighted periodically. The fractured surfaces of composites after impact test are examined by FEI Quanta 400F FESEM scanning electron microscope (SEM).

\section{RESULTS AND DISCUSSION}

\subsection{IR Analysis}

IR spectrum of neat BN and BN (S) samples are displayed in Figure 2. The peaks at range of $600 \mathrm{~cm}^{-1}$ and $1000 \mathrm{~cm}^{-1}$ wavenumbers are related with the $\mathrm{Si}-\mathrm{O}$ vibrations [31-33]. These peaks can be seen for neat $\mathrm{BN}$ since $\mathrm{BN}$ includes a considerable amount of silica in its chemical composition [34]. BN (S) gives higher intensity for these peaks due to silane layer on powder surface. The peak centered at about 1000 $\mathrm{cm}^{-1}$ stem from oxygen functionality. The intense peak at $1300 \mathrm{~cm}^{-1}$ comes from COO- stretching bonds [35,36]. BN (S) spectra has higher intensity for these peaks because of forming silanol bonds at powder surface. The two peaks between $2800 \mathrm{~cm}^{-1}$ and $2900 \mathrm{~cm}^{-1}$ wavenumbers assign alkyl groups which is result from silane coupling agent has propyl groups [37]. The characteristic hydroxyl peaks can be seen at about $3350 \mathrm{~cm}^{-1}$. These findings confirm that neat BN surface was covered by silane coupling agent. 


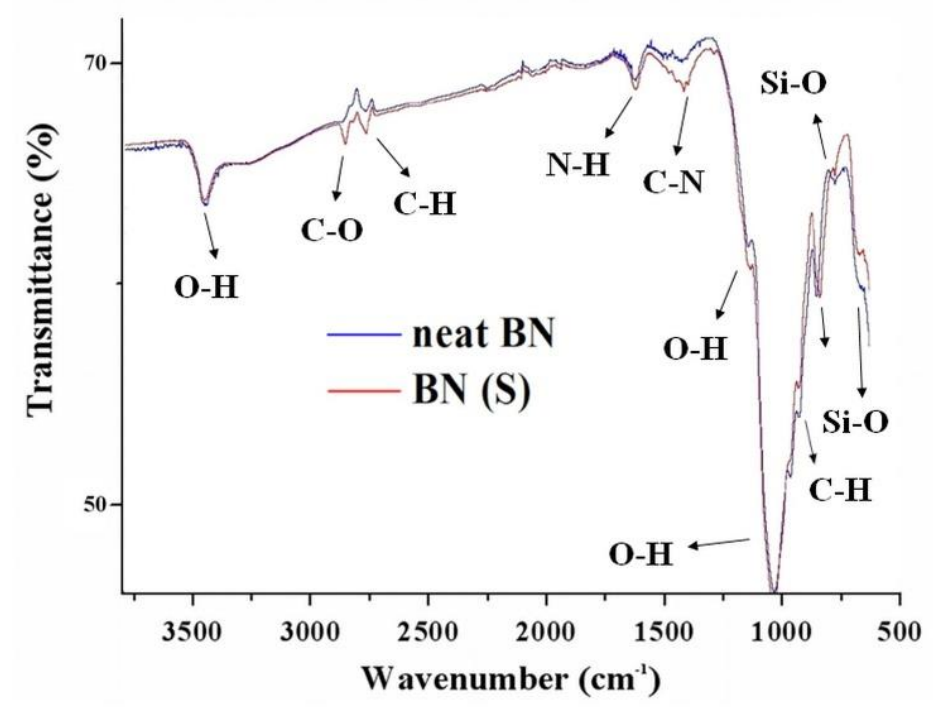

Figure 2. IR spectra of BN samples

\subsection{Mechanical Tests}

\subsubsection{Tensile test}

Mechanical test data of PLA and composites are listed in Table 2 and the tensile test curves are given in Figure 3.

Table 2. Mechanical test results

\begin{tabular}{lcccc}
\hline \multicolumn{1}{c}{ Samples } & $\begin{array}{c}\text { Tensile Strength } \\
\left(\mathbf{N} / \mathbf{m}^{\mathbf{2}}\right)\end{array}$ & $\begin{array}{c}\text { Tensile Modulus } \\
(\mathbf{G P a})\end{array}$ & $\begin{array}{c}\text { Elongation at } \\
\text { Break }(\mathbf{\%})\end{array}$ & $\begin{array}{c}\text { Impact Strength } \\
\left(\mathbf{k J} / \mathbf{m}^{\mathbf{2}}\right)\end{array}$ \\
\hline PLA & $58.4 \pm 1.6$ & $1.0 \pm 0.1$ & $11.6 \pm 0.7$ & $11.6 \pm 0.4$ \\
PLA-BN 5 & $58.7 \pm 1.4$ & $1.2 \pm 0.1$ & $8.2 \pm 0.5$ & $7.1 \pm 0.2$ \\
PLA-BN 10 & $60.2 \pm 1.9$ & $1.2 \pm 0.2$ & $9.3 \pm 0.8$ & $8.0 \pm 0.2$ \\
PLA-BN 15 & $63.6 \pm 1.8$ & $1.3 \pm 0.1$ & $8.4 \pm 0.7$ & $9.3 \pm 0.4$ \\
PLA-BN 20 & $60.5 \pm 1.6$ & $1.2 \pm 0.2$ & $8.1 \pm 0.6$ & $10.5 \pm 0.4$ \\
PLA-BN (S) 5 & $63.1 \pm 1.8$ & $1.3 \pm 0.2$ & $8.5 \pm 0.4$ & $11.4 \pm 0.3$ \\
PLA-BN (S) 10 & $64.2 \pm 2.0$ & $1.4 \pm 0.2$ & $8.7 \pm 0.4$ & $12.1 \pm 0.2$ \\
PLA-BN (S) 15 & $67.1 \pm 2.2$ & $1.4 \pm 0.2$ & $7.9 \pm 0.3$ & $13.7 \pm 0.3$ \\
PLA-BN (S) 20 & $63.5 \pm 1.9$ & $1.3 \pm 0.1$ & $8.6 \pm 0.5$ & $13.3 \pm 0.3$ \\
\hline
\end{tabular}

It can be seen from Table 2 that tensile strength increases with the filling ratio of $\mathrm{BN}$ towards to optimum concentration of $15 \mathrm{wt} \%$. Further additions of $\mathrm{BN}$ result with the reduction for tensile strength which may come from the formations of agglomeration of bentonite particles into PLA matrix at the highest concentration $(20 \mathrm{wt} \%)$. BN (S) containing composites give about 3 points higher tensile strength values as compared with the same concentrations of neat $\mathrm{BN}$. Increase of interfacial adhesion between BN and PLA may be the reason of these results. 


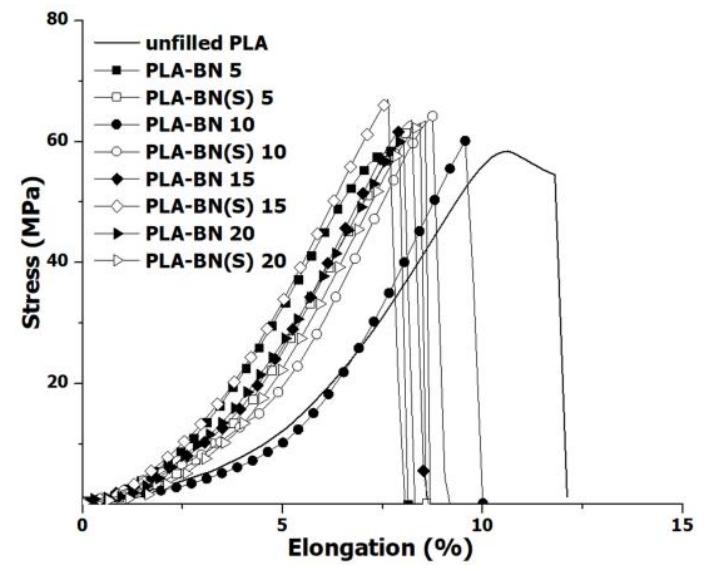

Figure 3. Tensile curve of PLA and composites

According to Figure 3, the highest elongation is obtained for unfilled PLA. Elongation at break value of PLA decreases approximately 3 points with the $\mathrm{BN}$ inclusions regardless of neat or silaned $\mathrm{BN}$ samples. On the other hand, composites display slightly higher tensile modulus than PLA according to Table 2.

\subsubsection{Impact test}

Impact strength results of unfilled PLA and composites can be seen in the last column of Table 2. Impact strength of composites are increased with increase in BN concentrations. Almost all of the BN (S) inclusions show higher impact strength values compared to unfilled PLA. BN (S) reinforced composites show about 3 points higher impact strength than neat BN at the same concentrations.
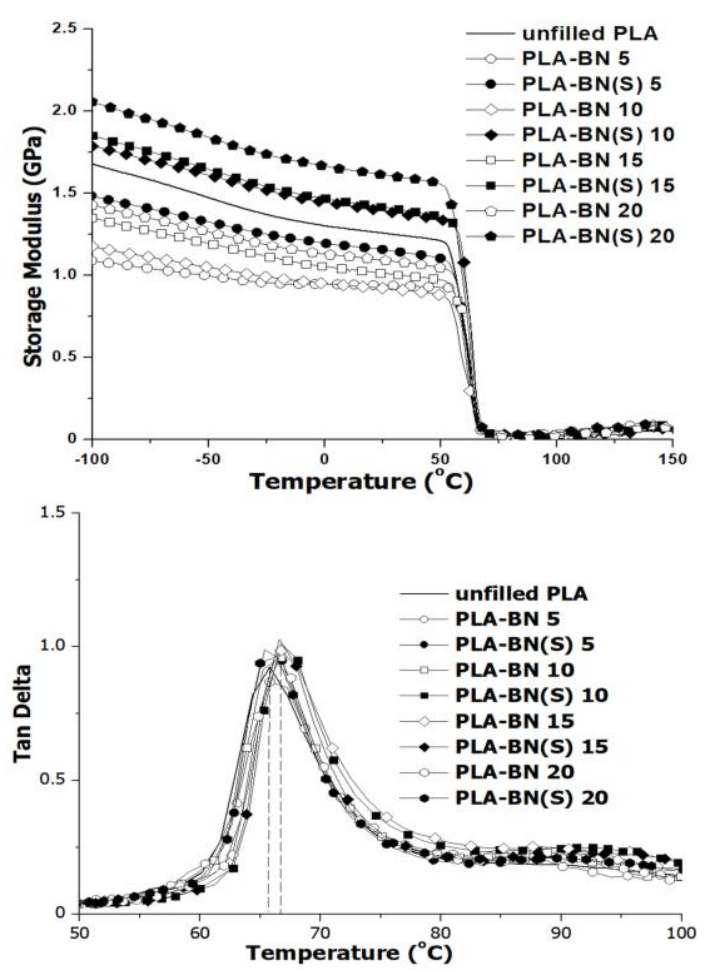

Figure 4. DMA test curves of PLA and composites. 


\subsection{Thermo-Mechanical Properties}

Storage modulus and tan delta curves obtained from DMA test data are displayed in Figure 4. Storage modulus curves decrease around $70^{\circ} \mathrm{C}$ which indicates the glass transition temperature $\left(\mathrm{T}_{\mathrm{g}}\right)$ of PLA. Storage modulus of PLA increases with neat BN additions at all filling ratios. BN (S) containing samples show higher storage modulus compared to neat BN. The highest modulus is found for PLA-BN (S) 20 composite. The maximum temperature at the peak of tan delta curve corresponds $T_{g}$ of PLA. $T_{g}$ values of neat PLA and PLA-BN (S) 10 composite are estimated from the tan delta curves as $65^{\circ} \mathrm{C}$ and $68^{\circ} \mathrm{C}$. $\mathrm{T}_{\mathrm{g}}$ of PLA increases with the additions of $\mathrm{BN}$ and $\mathrm{BN}(\mathrm{S}) .10 \% \mathrm{BN}(\mathrm{S})$ containing composite gives the highest $T_{g}$ value among samples. These findings indicate that the chain motions of PLA are restricted with addition of bentonite particles [38-41].

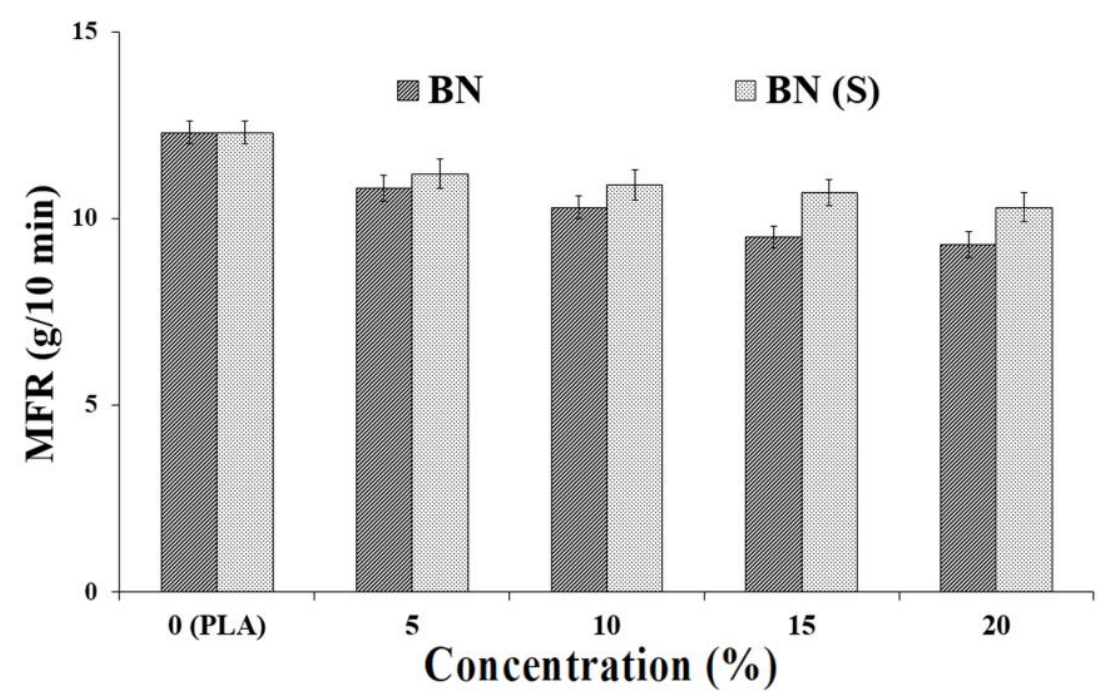

Figure 5. MFR results of PLA and composites.

\subsection{Melt-Flow Rate Test}

According to MFR values displayed in Figure 5, it can be said that all of the MFR values are found in a narrow range. This result indicates that processing of these composites can be performed without a hitch as the industrial scale production considered. BN and $\mathrm{BN}$ (S) inclusions cause negligible decrease for MFR of PLA. MFR values show decreasing trend with increase in BN concentration. It can be seen from the results that silane treated BN reinforced composites give higher MFR values than that of neat $\mathrm{BN}$. This is because of higher compatibility of BN (S) with PLA matrix relative to neat BN [42-45].

Table 3. Water absorption test results.

\begin{tabular}{lc}
\hline \multicolumn{1}{c}{ Samples } & Water Absorption (\%) \\
\hline PLA & $0.9 \pm 0.1$ \\
PLA-BN 5 & $1.6 \pm 0.1$ \\
PLA-BN 10 & $2.1 \pm 0.1$ \\
PLA-BN 15 & $2.5 \pm 0.2$ \\
PLA-BN 20 & $3.2 \pm 0.1$ \\
PLA-BN (S) 5 & $1.4 \pm 0.1$ \\
PLA-BN (S) 10 & $1.8 \pm 0.2$ \\
PLA-BN (S) 15 & $1.9 \pm 0.1$ \\
PLA-BN (S) 20 & $2.1 \pm 0.1$ \\
\hline
\end{tabular}




\subsection{Water Absorption}

Water absorption test data of samples for the time period of 15 days are listed in Table 3. Unfilled PLA sample gives an absorption value of $1 \%$ whereas BN containing composites absorb higher amount of water. Water uptake of composites increase with increase of BN concentration. PLA-BN (S) composites display lower water absorption values than neat BN samples at the same concentrations. This means that hydrophobic silanized surface of BN causes reduction in water uptake values for PLA based composites $[46,47]$.

\subsection{Morphological Study}

SEM micro-images of composites having the lowest (5\%) and the highest (20\%) filling ratios are shown in Figure 6. Formations of agglomerates for neat BN particles into PLA can be seen from the microimages of PLA-BN samples. On the other hand, BN (S) particles exhibit homogeneous dispersion inside the matrix. It can be seen from the SEM micro-image of PLA-BN (S) 5 that surface of BN particles are surrounded by PLA matrix. Some agglomeration regions are also observed for BN (S) at $20 \%$ concentration, however more agglomerated regions are seen for neat BN containing composite at the same filling ratio. These results confirm that well-dispersion and effective adhesion are achieved for silanized BN samples due to improvement of interfacial interactions between two phases.
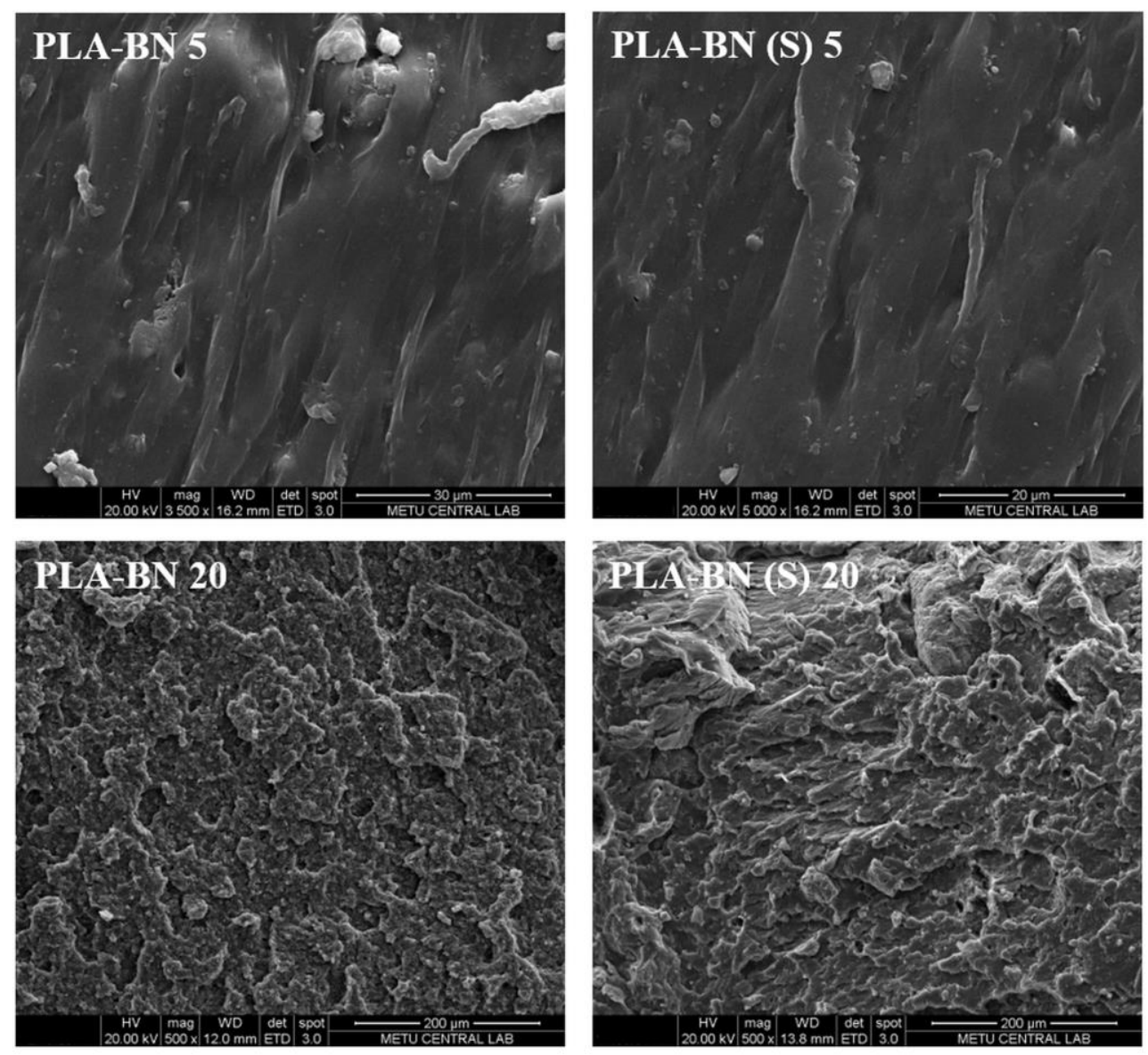

Figure 6. SEM micro-images of composites. 


\section{CONCLUSION}

In this study, effects of surface silanization and concentration of Turkish bentonite mineral on mechanical, thermo-mechanical, melt flow, water uptake and morphological properties of PLA based composites are reported. IR analysis confirms that surface of neat $\mathrm{BN}$ is covered by silane coupling agent after silanization process. According to mechanical test results, silanized BN containing PLA composites display higher tensile strength and impact strength relative to neat BN samples. The optimum BN concentration is obtained as $15 \mathrm{wt} \%$ in the case of tensile strength and impact strength results. Additions of BN powders cause slight decrease in elongation of unfilled PLA. DMA test reveals that storage modulus of PLA is improved with the addition of BN (S). Glass transition temperature of PLA increases after addition of BN powders. All of the composites show lower MFR values compared to unfilled PLA; however, these reductions can be considered as negligible to cause processing problems of composites. Water absorption test data shows that incorporation of BN sample increases of water uptake of unfilled PLA. Silanized BN reinforced composites exhibit lower water absorption compared to neat BN because of hydrophobicity of silane containing surface. According to SEM analysis, BN (S) particles display more homogeneous dispersion than neat BN into PLA matrix. These outcomes indicate that application of silanization process on $\mathrm{BN}$ powders resulted in significant improvement of mechanical and physical performance of PLA based composites due to increase in compatibility between two phases.

\section{REFERENCES}

[1] Mohanty AK, Misra M, Drzal LT. Sustainable bio-composites from renewable resources opportunities and challenges in the green materials world. J Polym Environ 2002; 10(1-2): 19-26.

[2] Andreopoulos AG, Theophanides T. Degradable plastics: A smart approach to various applications. J Elastom Plastics 1994; 26(4): 308-326.

[3] Bismarck A, Baltazar A, Jimenez Y, Sarikakis K. Green composites as panacea? Socio-economic aspects of green materials. Environ Dev Sustain 2006; 8(3): 445-463.

[4] Tayfun U. Influence of surface treatment of fillers on the mechanical properties of thermoplastic polyurethane composites. PhD, Middle East Technical University, Ankara, Turkey, 2015.

[5] Bajpai PK, Singh I, Madaan J. Development and characterization of PLA-based green composites: A review. J Thermoplast Compos Mater 2012; 27: 52-81.

[6] Weber CJ, Haugaard V, Festersen R, Bertelsen G. Production and applications of biobased packaging materials for the food industry. Food Addit Contam 2002; 19: 172-177.

[7] Murariu M, Dubois P. PLA composites: From production to properties. Adv Drug Deliv Rev 2016; 107: $17-46$.

[8] Eselini N, Tirkes S, Akar AO, Tayfun U. Production and characterization of poly (lactic acid)based biocomposites filled with basalt fiber and flax fiber hybrid. J Elastom Plast 2019; DOI: $10.1177 / 0095244319884716$

[9] Rasal RM, Janorkar AV, Hirt DE. Poly (lactic acid) modifications. Prog Polym Sci 2010; 35: 338356.

[10] Ren J. Biodegradable Poly (lactic acid): Synthesis, Modification, Processing and Applications. Springer: Verlag, 2011. 
[11] Alghadi AM, Tirkes S, Tayfun U. Mechanical, thermo-mechanical and morphological characterization of ABS based composites loaded with perlite mineral. Mater Res Express 2020; 7: 015301.

[12] Theberge JE. Mineral reinforced thermoplastic composites. J Elastom Plast 1982; 14(2): 100-108.

[13] Xanthos M. Functional Fillers for Plastics. Weinheim, Wiley VCH, 2005.

[14] Fu S, Feng X, Lauke B, et al. Effects of particle size, particle/matrix interface adhesion and particle loading on mechanical properties of particulate-polymer composites. Compos Part B Eng 2008; 39: 933-961.

[15] Oktem GA, Tincer T. Preparation and characterization of perlite-filled high- density polyethylenes: 1. Mechanical Properties. J Appl Polym Sci 1994; 54: 1103-1114.

[16] Metin D, Tihminhoglu F, Balkose D, Ulku S. The effect of interfacial interactions on the mechanical properties of polypropylene/natural zeolite composites. Compos Part A Appl Sci Manuf 2004; 35(1): 23-32.

[17] Kanbur Y, Tayfun U. Mechanical, physical and morphological properties of acidic and basic pumice containing polypropylene composites. Sakarya Univ J Sci 2018; 22(2): 333-339.

[18] Klein C, Hurlbut CS. Manual of Mineralogy. 21st ed. USA: Wiley, 1998.

[19] Esenli F, Sans BE. XRD studies of opals ( $4 \AA$ peak) in bentonites from Turkey: Implications for the origin of bentonites. J Min Geochem 2013; 191(1): 45-53.

[20] Bulut G, Chimeddorj M, Esenli F, Çelik MS. Production of desiccants from Turkish bentonites. Appl Clay Sci 2009; 46: 141-147.

[21] De Oliveira SV, Araújo EM, Pereira CMC, Leite AMD. Polyethylene/bentonite clay nanocomposite with flame retardant properties. Polimeros 2017; 27: 91-98.

[22] Seyidoglu T, Yilmazer U. Use of purified and modified bentonites in linear low-density polyethylene/organoclay/compatibilizer nanocomposites. J Appl Polym Sci 2012; 124(3): 24302440.

[23] Durmus A, Woo M, Kasgoz A, Macosko CW, Tsapatsis M. Intercalated linear low density polyethylene (LLDPE)/clay nanocomposites prepared with oxidized polyethylene as a new type compatibilizer: Structural, mechanical and barrier properties. Eur Polym J 2007; 43(9): 3737-3749.

[24] Kraus E, Nguen D-A, Efimova A, Starostina I, Stoyanov O. Acid-base properties of polyethylene composites with clays. J Appl Polym Sci 2016; 133(30): 43629.

[25] Liborio P, Oliveira VA, Marques MFV. New chemical treatment of bentonite for the preparation of polypropylene nanocomposites by melt intercalation. Appl Clay Sci 2015; 111: 44-49.

[26] Seyidoglu T, Yilmazer U. Modification and characterization of bentonite with quaternary ammonium and phosphonium salts and its use in polypropylene nanocomposites. $\mathrm{J}$ Thermoplast Compos Mater 2015; 28: 86-110. 
[27] Yurddaskal M, Celik E. Effect of halogen-free nanoparticles on the mechanical, structural, thermal and flame retardant properties of polymer matrix composite. Compos Struct 2018; 183(1): 381388.

[28] Kausar A, Haider S, Muhammad B. Nanocomposite based on polystyrene/polyamide blend and bentonite: morphology, thermal, and nonflammability properties. Nanomater Nanotechno 2017; 7 : $1-14$.

[29] Hacioglu F. Degradation of polycarbonate, bentonite, barite, carbon fiber and glass fiber filled polycarbonate via gamma irradiation and possible use of polycarbonate in radioactive waste management. PhD, Middle East Technical University, Ankara, Turkey, 2017.

[30] Guven O, Karakas F, Kaya MA, Yildirim H, Celik MS. Composite films based on styrene-cobutyl-acrylate with colemanite and calcium bentonite mineral fillers. Mech Compos Mater 2014; 50(3): 335-342.

[31] Shokoohi S, Arefazar A, Khosrokhavar R. Silane coupling agents in polymer-based reinforced composites: A review. J Reinf Plast Compos 2008; 27(5): 473-485.

[32] Hatipoglu A, Dike AS. Effects of concentration and surface silanization of barite on the mechanical and physical properties of poly (lactic acid)/barite composites. Polym Polym Compos 2020; 28(2): $140-148$.

[33] Yang R, Liu Y, Wang K, Yu J. Characterization of surface interaction of inorganic fillers with silane coupling agents. J Anal Appl Pyrol 2003; 70(2): 413-425.

[34] Rice SB, Freund H, Clouse JA, Fleissner TG, Isaacs CM. Application of fourier transform infrared spectroscopy to silica diagenesis: the opal-A to opal-CT transformation. J Sediment Res 1995; 65: 639-647.

[35] Dogan SD, Tayfun U, Dogan M. New route for modifying cellulosic fibers with fatty acids and its application to polyethylene/jute fiber composites. J Compos Mater 2016; 50(18): 2475-2485.

[36] Silverstein R, Webster F. Spectrometric identification of organic compounds. New York, NY, USA: Wiley, 2006.

[37] Bouchet J, Pax GM, Leterrier Y, et al. Formation of aminosilane-oxide interphases. Compos Interface 2006; 13(7): 573-588.

[38] Ozdemir E, Hacaloglu J. Characterization of polymer/nanoclay composites via direct pyrolysis mass spectrometry. J Anal Appl Pyrol 2018; 134: 395-404.

[39] Tayfun U, Dogan M. Improvement the dyeability of poly(lactic acid) fiber using organoclay during melt spinning. Polym Bull 2016; 73(6):1581-1593.

[40] Donnet JB. Nano and microcomposites of polymers elastomers and their reinforcement. Compos Sci Technol 2013; 63: 1085-1088.

[41] Dike AS, Yilmazer U. Mechanical, thermal and rheological characterization of polystyrene/organoclay nanocomposites containing aliphatic elastomer modifiers. Mater Res Express 2020; 7: 015055 . 
[42] Tayfun U, Dogan M, Bayramli E. Polyurethane elastomer as a matrix material for short carbon fiber reinforced thermoplastics. Anadolu Univ J Sci Technol A Appl Sci Eng 2017; 18(3): 682694.

[43] Tian HY, Tagaya H. Preparation, characterization and mechanical properties of the polylactide/perlite and the polylactide/montmorillonite composites. J Mater Sci 2007; 42: 32443250 .

[44] Dike AS. Nanocomposites based on blends of polystyrene. PhD, Middle East Technical University, Ankara, Turkey, 2011.

[45] Ge C, Ding P, Shi L, Fu J. Isothermal crystallization kinetics and melting behavior of poly(ethylene terephthalate)/barite nanocomposites, J Polym Sci B Polym Phys 2009; 47: 655-668.

[46] Tayfun U, Dogan M, Bayramli E. Investigations of the flax fiber/thermoplastic polyurethane ecocomposites: Influence of isocyanate modification of flax fiber surface. Polym Compos 2017; 38(12): 2874-2880.

[47] Arbelaiz A, Fernández B, Ramos JA, Retegi A, Llano-Ponte R, Mondragon I. Mechanical properties of short flax fibre bundle/polypropylene composites: Influence of matrix/fibre modification, fibre content, water uptake and recycling. Compos Sci Technol 2005; 65(10): 15821592. 